\title{
Liste des conventions d'écriture et abréviations utilisées dans la GGHF
}

Des abréviations spécifiques sont utilisées dans la partie Phonétique Historique $(\rightarrow 12.6 .2)$.

\section{Conventions d'écriture}

$<\mathrm{E}>$

$<\mathrm{p}>$

$[\mathrm{p}]$

$/ \mathrm{p} /$

JE (capitales)

poire (italiques)

pira (soulignement)

*cuimes

'seniori

$>$

$<$

CIST (petites capitales)

CIEL (petites capitales)

'tête' (guillemets simples)

$\rightarrow$ chap. $33, \rightarrow 33.2$

voir 32.1

\section{Abréviations}

$c a$

p. ex.

litt.

sc.

s.v.

vs.

av. JC / ap. JC

dp.

LClass

TAF

AF

MF

FPréclass

FClass

FMod

FContemporain

Adj

Adv

Att

B

COD

COI archigraphème

segment graphique / graphème

transcription phonétique / segment phonique

transcription phonologique / phonème

lemme

étymon et forme attestée, $\mathrm{p}$. ex. la forme poire vient de pira

voyelle tonique

forme ou expression agrammaticale ou non attestée (précédée du signe *)

forme reconstruite (précédée du signe ${ }^{\circ}$ )

devient, p. ex. lat. caput $>\mathrm{AF}$ chief

vient de, p. ex. AF chief $<$ lat. caput

paradigme

concept désigné par une expression linguistique, p. ex. lat. caelum CIEL

sens linguistique / traduction en FMod

renvoi à un autre chapitre (ou sous-chapitre) de la GGHF

renvoi à un sous-chapitre à l'intérieur du chapitre

circa

par exemple

littéralement

scilicet (à savoir)

sub voce (sous l'entrée $x$ du dictionnaire cité)

versus

avant Jésus Christ / après Jésus Christ

depuis

latin classique

très ancien français $\left(9^{\mathrm{e}}-11^{\mathrm{e}} \mathrm{s}\right.$.)

ancien français $\left(12^{\mathrm{e}}-13^{\mathrm{e}} \mathrm{s}\right.$.)

moyen français (1300-1550)

français pré-classique (1550-1650)

français classique (1650-1800)

français moderne (1800-2000)

français contemporain $\left(21^{\mathrm{e}} \mathrm{s}\right.$.)

adjectif

adverbe

attribut

base (verbale)

complément d'objet direct

complément d'objet indirect 
CR fem. pl.

CS masc. sg.

dér.

Det

fém.

GAdj

GN

GPrep

GV

INC

INJ

INT

loc.

masc.

$\mathrm{N}$

n.f.

n.m.

n.n.

num.card.

$\mathrm{O}$

Od

Oi

On

Op

$\mathrm{Oq}$

Os

$\mathrm{P} 1, \ldots, \mathrm{P} 5, \ldots$

pl.

$\mathrm{S}$

S0

S-autres

Sdem

sg.

Sind

Snom

$\mathrm{Sp}$

Spm

Spos

Spp

Srel

Ssub

suff.

$\mathrm{V}$

v.ditr.

v.intr.

v.tr.

all.

angl.

angl. amér.

arag.

arg. cas régime féminin pluriel

cas sujet masculin singulier

dérivé

déterminant

féminin

groupe adjectival

groupe nominal

groupe prépositionnel

groupe verbal

proposition incise

proposition injonctive

proposition interrogative

locution

masculin

nom

nom féminin

nom masculin

nom neutre

numéro cardinal

objet

objet pronom démonstratif

objet pronom indéfini

objet nominal

objet pronom personnel

objet pronom relatif

objet propositionnel

$1^{\text {ère }}$ p. sg. (JE), .., $2^{\mathrm{e}}$ p. pl. (VOUS)...

pluriel

sujet

sujet non exprimé

inclut l'ensemble des Sdem, Sind, Srel, Spos et Ssub

sujet pronom démonstratif

singulier

sujet pronom indéfini

sujet nominal

sujet pronominal (inclut les Spp et Spm)

sujet pronom impersonnel

sujet pronom possessif

sujet pronom personnel

sujet pronom relatif

sujet propositionnel

suffixe

verbe

verbe ditransitif

verbe intransitif

verbe transitif

allemand

anglais

anglais américain

aragonais

argotique 


$\begin{array}{ll}\text { ast. } & \text { asturien } \\ \text { cat. } & \text { catalan } \\ \text { chin. } & \text { chinois } \\ \text { esp. } & \text { espagnol } \\ \text { fam. } & \text { familier } \\ \text { fr. } & \text { français } \\ \text { frioul. } & \text { frioulan } \\ \text { frprov. } & \text { francoprovençal } \\ \text { gal. } & \text { galicien } \\ \text { gasc. } & \text { gascon } \\ \text { gaul. } & \text { gaulois } \\ \text { germ. } & \text { germanique } \\ \text { got. } & \text { gotique } \\ \text { gr. } & \text { grec } \\ \text { it. } & \text { italien } \\ \text { jap. } & \text { japonais } \\ \text { lat. } & \text { latin } \\ \text { néerl. } & \text { néerlandais } \\ \text { occ. } & \text { occitan } \\ \text { pop. } & \text { populaire } \\ \text { port. } & \text { portugais } \\ \text { protorom. } & \text { proto-roman } \\ \text { rhétorom. } & \text { rhétoroman } \\ \text { roum. } & \text { roumain } \\ \text { sarde camp. } & \text { sarde campidanais } \\ \text { sarde log. } & \text { sarde logoudorien }\end{array}$


